\title{
Alien balsams, strawberries and their pollinators in a warmer world
}

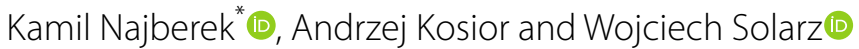

\begin{abstract}
Background: Strawberries are a common crop whose yield success depends on the availability of pollinators. Invasive alien plants, such as Impatiens glandulifera and I. parviflora, are also attractive for bees and hoverflies, respectively, and occur in close proximity to strawberry cultivation areas. The aim of the study was to test whether alien plants may decrease pollination of strawberry cultivation. However, even if the pollinators are abundant, efficiency of their pollination may decrease as a result of revisits of flowers that were already probed. It is addressed by pollinators by scent marking. Moreover, such revisits can be determined by nectar replenishment, which may occur rapidly in nectar-rich flowers. We studied revisits to I. glandulifera by bumblebees and defined the factors that influence the probability of revisits (air temperature; pollinator species; family caste and size; flower area; sun radiation; and time of day).

Results: We found that the two alien species decreased the number of pollinators visiting strawberries. Apoidea, Bombini and Syrphidae significantly decreased on Fragaria $\times$ ananassa when alien Impatiens were present. We also revealed the influence of increasing air temperature on bumblebee foraging, which was particularly significant for female workers. At very high temperatures $\left(>37^{\circ} \mathrm{C}\right)$, bumblebee males revisited probed flowers less often than female workers.

Conclusions: Our results demonstrate that in experimental conditions attractive alien species decrease pollination of strawberries, which may negatively affect production of this crop. Although the results have not been verified in real-life strawberry fields yet, we recommend that alien plant species that share the same pollinators and occur in close proximity of strawberries are controlled. Moreover, we found that revisits of probed flowers may weaken feeding efficiency of bumblebees. If revisits are not induced by nectar replenishment, then global warming may pose a serious threat to the survival of colonies, which may have consequences also for the plants that attract them, e.g., for strawberries.
\end{abstract}

Keywords: Biological invasions, Crop yield, Alien plant control, Male bumblebee, Role of CHCs, Climate change

\section{Background}

Pollination by wild insects is one of the key ecosystem services and plays an essential role in world crop production for human food [1]. Flowers of crops pollinated by wild pollinators produce twice as much fruit as flowers pollinated by the similar number of honey bees, Apis mellifera [2]. It is also known that in crop farms localized

*Correspondence: najberek@iop.krakow.pl

Institute of Nature Conservation, Polish Academy of Sciences, Al. Adama Mickiewicza 33, 31-120 Kraków, Poland in areas with a high number of wild pollinators, the frequency of flower visitors is higher and the pollination process is enhanced [3, 4]. An example of such a crop is strawberry, Fragaria $\times$ ananassa, which is a very important and widely cultivated crop. In Spain alone, as many as 367000 tons of strawberries per year are produced across 9700 ha of fields [5]. Strawberries are valued for their taste and nutritional properties, including their antioxidant and anti-inflammatory effects on the nervous system [e.g., 6]. This species is mainly wind pollinated; however, if insect pollen transport does not occur, then 
the pollination rate rarely exceeds $60 \%[7,8]$. Moreover, for strawberry, the absence of pollinators decreases the fruit weight [7-10] and increases the malformation probability $[9,11,12]$ while the presence of pollinators results in better fruit quality and increases total fruit production $[8,9,13,14]$.

Wild-growing invasive alien plant species have been shown to tempt pollinators away from native wild plants [e.g., 15]. An opposite scenario is also possible, because invasive alien plants growing in high-density populations could also act as "magnet" species that increase pollination of neighboring native plants [16]. However, these mechanisms have not been experimentally studied to date in cultivated plants. To bridge this gap, we selected two invasive alien plant species, Himalayan balsam (Impatiens glandulifera) and small balsam (I. parviflora) and tested whether they may decrease pollinators availability in cultivations of strawberry (Fragaria $\times$ ananassa) or conversely, enhance the pollination effect of this crop. The flowering periods of the three species overlap. Apidae (as in the case of I. glandulifera) and syrphidae (as in the case of I. parviflora) are common pollinators of Fragaria $\times$ ananassa $[7,17]$. Therefore, it is likely that the two alien plants may decrease pollination of strawberries. In the study area (Małopolska, SE Poland), the two balsams occur regularly in close proximity to strawberry fields (Najberek, pers. observ.). It should also be stressed that I. glandulifera is a highly invasive alien species that is widely distributed throughout Europe while I. parviflora is invasive in central and northern parts of the continent [18]. I. glandulifera is the best nectar-rewarding plant in Europe (with nectar production of $0.3 \mathrm{mg}$ per flower per hour), which probably determines its remarkable attractiveness for Apidae [15]. The production of nectar in flowers of I. glandulifera far exceeds its production in I. parviflora $[19,20]$. On the other hand, the success of I. parviflora is driven mainly by its autonomous selfing ability [20]; in addition, its nectar is very attractive for many species of syrphidae [21-23].

The importance of plant-pollinator interactions for crops is associated not only with their diversity and numbers but also with their pollination efficiency [24]. Even if alien plant species do not decrease pollination of crops, the visitors of the flowers may be less efficient. The reason could be that a range of different factors, including weather conditions, may cause pollinators to more frequently revisit flowers that were already probed. In this regard, avoiding "empty" flowers that have been recently visited is of paramount importance not only for pollinators but also for crops. Any factor that decreases the effectiveness of pollinators represents a potential loss of the plant's reproductive success [24]. It is known that bumblebees can detect their own scent marks secreted on visited flowers to avoid revisiting them during the foraging flight [25-29], and they also recognize flowers that have already been visited by their siblings, conspecifics or even by individuals from other bumblebee colonies. An underlying mechanism is that while pollinating, bumblebees secrete a mixture of hydrocarbons from their glandular systems associated with the claw retractor tendon of legs [30]. The process is essential for bumblebee colony economy because it saves time probing empty flowers and consequently results in an increase in the efficiency of pollen and nectar collection [25-29]. This efficiency is mostly affected by the choice of flower; therefore, incorrect decision-making may have negative consequences for bumblebees as well as for plants that attract them to transfer their pollen [24]. On the other hand, examples have been observed when revisits of flowers could play a positive role and should not be considered incorrect decisions. A previous study demonstrated [31] that some plants can replenish nectar within minutes, which may attract a pollinator even during the same foraging flight. This replenishment may be determined by nectar removal and supported by the airborne sound of the pollinator [32], its touch [33] and its vibration [34]. Considering the extraordinary abilities in nectar production of highly invasive alien plants (such as I. glandulifera [15]), the role of nectar replenishment in plant-pollinator interactions can be significant.

We defined factors that influence the probability of revisits of probed flowers of I. glandulifera by their bumblebee pollinators, with the main focus on air temperature. Although the negative role of increasing air temperature on plant-pollinator interactions has been broadly discussed [35-39], knowledge of the impact of temperature on scent-marking is still limited. To date, temperature has been shown to alter the efficacy of sexual chemical signals in the mountain lizard Iberolacerta cyreni [40] and female oviposition behaviour and the perception of infochemicals emitted by larvae of the ladybeetle Adalia bipunctata [41]. In turn, although the impact of increasing temperature on nectar replenishment was not investigated using Impatiens species, investigations using other plants showed that moderately elevated temperatures may facilitate nectar secretion while very high temperatures reduce nectar secretion [e.g., 42, 43]. Time of the day was also included in the study design because the activity of pollinators of Impatiens species may change as the day progresses [44, 45], which could be associated with diurnal changes in the amount of nectar. Another factor was the level of sun radiation because light intensity can constrain foraging efficiency [46]. Moreover, the size of visited flowers and the caste of pollinators were taken into account because they may affect both the search time of initially visited 
flowers and the flight behaviour of foraging bumblebees [47-49].

In this study we conducted two experiments to address two research questions. Firstly, whether wild-growing invasive alien plant species decrease pollination of cultivated plants, or conversely, they act as magnet species and increase the pollination rate of crops. Secondly, whether the increasing number of revisits of flowers that were already probed (lowering efficiency of pollination) is influenced by the weather, including rising air temperature.

\section{Results}

\section{Experiment 1: Invasive alien species decrease pollination of cultivated species}

In total, we recorded 3241 pollinators (Online Resource, Table S1), and $27.0 \%$ were identified at the species level while $35.8 \%$ were identified at the family level. In addition, $36.6 \%$ belonged to the Bombus lucorum complex, and few records $(0.5 \%$ in total) were attributed to superfamilies, genera and tribes. The dominant pollinator groups of I. parviflora and Fragaria $\times$ ananassa were different from those of I. glandulifera (Fig. 1; Online Resource, Table S1). In the two former species, the dominant group was Syrphidae (e.g., Episyrphus balteatus and E. corolla; Fig. 1; Online Resource, Table S1), while in I. glandulifera, the dominant group was Bombini ( $B$. lucorum-complex, Bombus pascuorum, B. terrestris and
B. hypnorum; Fig. 1; Online Resource, Table S1). Interestingly, although bumblebees were not very abundant on Fragaria $\times$ ananassa (Fig. 1; Online Resource, Table S1), as many as 6 bumblebee species visited their flowers (B. pascuorum, B. lucorum-complex, B. terrestris, $B$. humilis, B. pratorum and Psithyrus vestalis; Online Resource, Table S1). The share of Apidae pollinators was also substantial (Fig. 1). For example, A. mellifera was an important pollinator of I. glandulifera and also occurred on Fragaria $\times$ ananassa (Online Resource, Table S1). Formicidae, which is known to include nectar thieves, occurred on Fragaria $\times$ ananassa and occasionally on $I$. parviflora (Online Resource, Table S1). It should also be noted that when the cultivated plant (Fragaria $\times$ anana$s s a$, "Fr") was exposed together with the alien plant ( $I$. glandulifera or I. parviflora, "Im"), Variant 3 (FrIm), only a small number of recorded pollinators visited both surveyed plant species during a single flight $(\mathrm{N}=35,1.1 \%$; including 33 Syrphidae and 2 Diptera taxa). All those cases were recorded only in the tests of strawberries and I. parviflora.

In statistical analysis the GLMM model with two fixed effects ('Variant and species', 'Stem height') and two random factors ('Plant ID', 'Time intervals') was selected (Table S2). In the model, 'Variant and species' variable played a crucial role $(\mathrm{F}=2.04, \mathrm{df}=1420, p$ $=0.047)$. We revealed that the number of pollinators of Fragaria $\times$ ananassa was significantly higher when

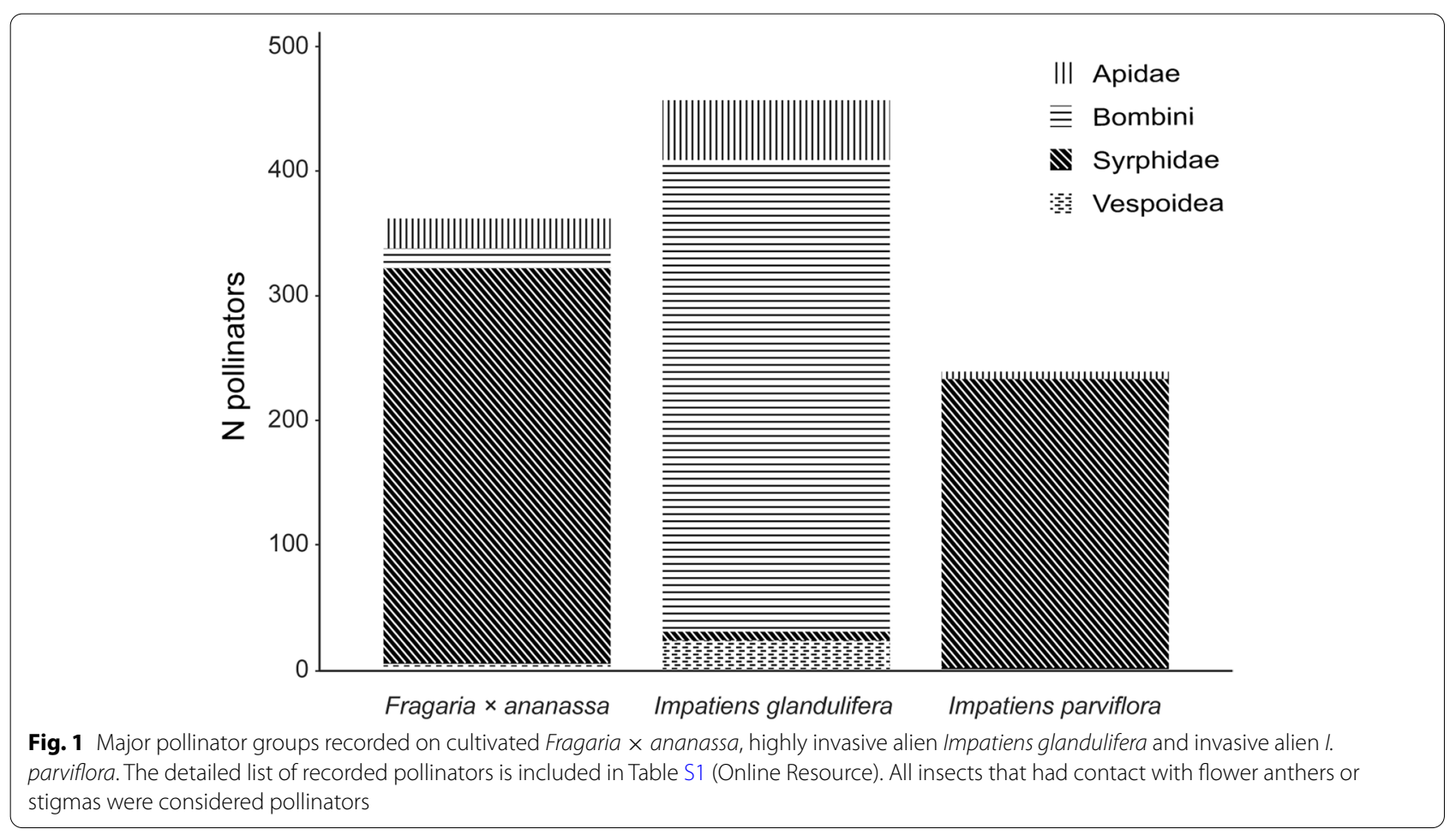


the species was exposed alone (Fr) than when it was exposed together with the highly invasive I. glandulifera (FrIm) (contrast: $\mathrm{SE}=0.35, \mathrm{t}=-1.95, \mathrm{df}=1413, p$ $=0.052$; Fig. 2). In contrast, the number of pollinators of I. glandulifera tended to rise when the two species were exposed together (FrIm) (contrast: $\mathrm{SE}=0.10, \mathrm{t}=$ 1.81, $\mathrm{df}=1413, p=0.070$; Fig. 2).

In addition, we compared the number of records of Bombini, Syrphidae, Apoidea and Vespoidea in particular plant arrangement variants (Im, Fr and FrIm) using proportion tests (Table 1). We found that the total numbers of Bombini and Syrphidae recorded on Fragaria $\times$ ananassa were significantly higher when it was the only species available (Fr; Table 1 ) than when it was accompanied by I. glandulifera (FrIm; Table 1). At the same time, we found that the number of Bombini recorded from the latter species was significantly lower in the Im variant than in tests together with Fragaria $\times$ ananassa (FrIm) (Table 1). Interestingly, the number of Apoidea visiting I. glandulifera solely (Im) was higher than in the tests with Fragaria $\times$ ananassa (FrIm) (Table 1).

Although the overall result of the GLMM model for Fragaria $\times$ ananassa and I. parviflora did not reveal any between-species differences (Fig. 2), such differences were found in the proportion tests (Table 1). The numbers of Apoidea, Bombini and Syrphidae recorded from Fragaria $\times$ ananassa were significantly lower with (FrIm) than without (Fr) the alien species (Table 1). However, it should also be noted that the number of Syrphidae recorded from I. parviflora in the FrIm variant with Fragaria $\times$ ananassa also decreased (Table 1 ).

The GLMM model also revealed that taller plants were more frequently visited by pollinators than shorter plants $(\mathrm{F}=16.73, \mathrm{df}=1414, p<0.001)$. The number of flowers and air temperature did not influence the results (Online Resource, Table S2). Datasets on the stem height of surveyed plant individuals are included in Table S3 (Online Resource).

\section{Experiment 2: Revisiting flowers increases with air temperature}

In 2019, revisits of I. glandulifera flowers by bumblebees amounted to $24.4 \%$ of all visits (total $\mathrm{N}$ of visited flowers $=1434$ ) paid during 195 flights. During a single bumblebee flight, 278 flowers had 2 revisits (19.4\%), 61 had 3 revisits $(4.25 \%), 10$ had 4 revisits $(0.7 \%)$ and one had 5 revisits $(0.07 \%)$. We recorded flights of the $B$. lucorum complex $(N=105), B$. pascuorum $(N=49)$ and $B$. terrestris $(N=41)$. The GLMM model with three fixed effects ('Temperature,' 'Pollinator,' 'Cloud cover') and one random factor ('Plant ID') was selected (Table S2). The result was affected by air temperature and bumblebee species (Table 2). The same flowers were revisited more frequently when the air temperature was higher (Table 2; Online Resource, Fig. S1). A similar tendency was also found in sunny weather in comparison to partially sunny weather (Table 2; Online Resource, Fig. S2); in turn, in cloudy weather the results did no differ from both sunny/partially sunny weather (Table 2; Online Resource,

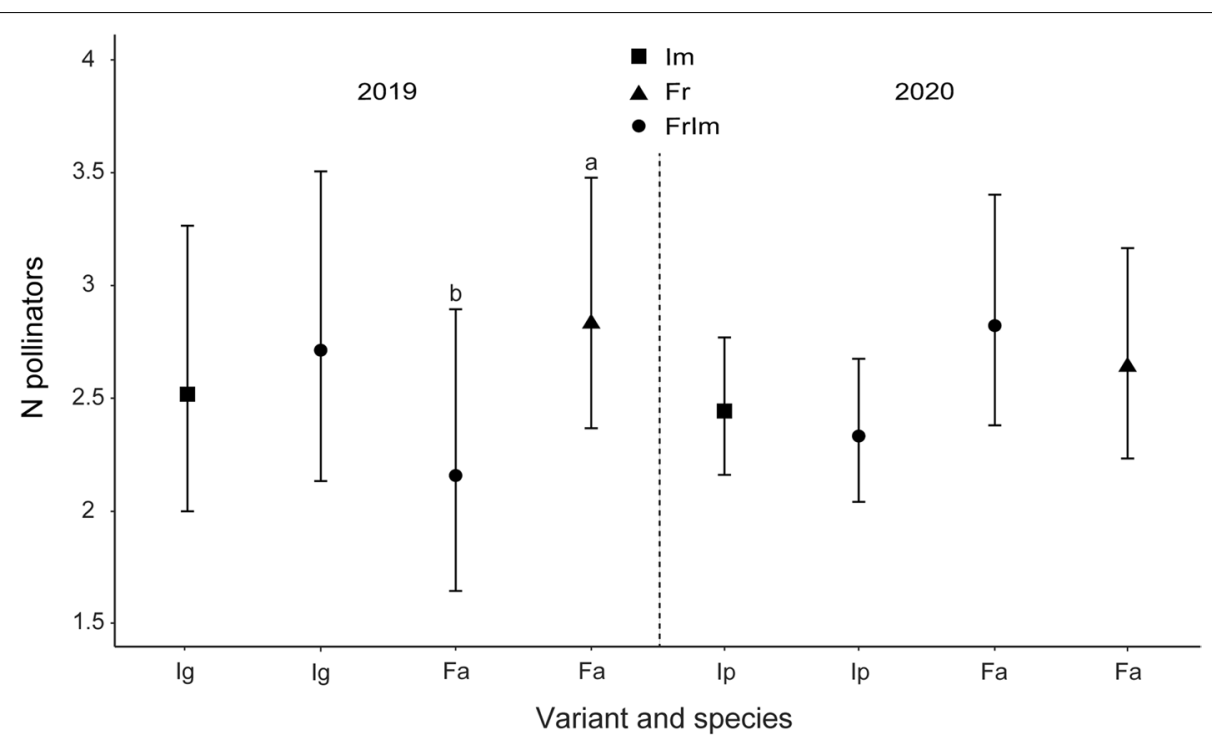

Fig. 2 Estimated mean number of pollinators ( \pm confidence intervals) recorded from highly invasive alien Impatiens glandulifera - 'Ig', invasive alien I. parviflora -'Ip' and cultivated Fragaria $\times$ ananassa - 'Fa' in the three study variants: Im (alien species exposed solely), Fr (cultivated species exposed solely) and Frlm (alien and cultivated species exposed together). Letters above the T-bars indicate a significant decrease in the number of recorded pollinators from Fragaria $\times$ ananassa for tests carried out without I. glandulifera (letter "a") and with I. glandulifera (letter "b") 
Table 1 Number of pollinators per taxon group, recorded from highly invasive alien Impatiens glandulifera - 'Ig', invasive alien I. parviflora - 'Ip' and cultivated Fragaria $\times$ ananassa - 'Fa' in the three study variants: Im (alien species exposed solely), Fr (cultivated species exposed solely) and Frlm (alien and cultivated species exposed together). All insects that had contact with flower anthers or stigmas were considered pollinators

\begin{tabular}{|c|c|c|c|c|c|}
\hline Plant species & $\begin{array}{l}\text { Species } \\
\text { combination }\end{array}$ & Variant & Pollinator group & $\mathrm{N}$ records & Proportion test \\
\hline \multirow[t]{10}{*}{ Fragaria $\times$ ananassa } & $\mathrm{Fa}$ & $\mathrm{Fr}$ & Apoidea & 17 & \multirow[t]{2}{*}{ Fa vs Fa/lp: $X 2=28.73, p<0.001$} \\
\hline & $\mathrm{Fa} / \mathrm{Ip}$ & Frlm & Apoidea & 2 & \\
\hline & $\mathrm{Fa}$ & $\mathrm{Fr}$ & Bombini & 19 & \multirow{3}{*}{$\begin{array}{l}\text { Fa vs Fa/lp: } X 2=28.73, p<0.001 \\
\text { Fa vs Fa/lg: } X 2=32.68, p<0.001\end{array}$} \\
\hline & $\mathrm{Fa} / \mathrm{Ip}$ & Frlm & Bombini & 5 & \\
\hline & $\mathrm{Fa} / \lg$ & Frlm & Bombini & 2 & \\
\hline & $\mathrm{Fa}$ & $\mathrm{Fr}$ & Syrphidae & 320 & \multirow{3}{*}{$\begin{array}{l}\text { Fa vs Fa/lp: } X 2=61.03, p<0.001 \\
\text { Fa vs Fa/lg: } X 2=581.79, p<0.001\end{array}$} \\
\hline & $\mathrm{Fa} / \mathrm{Ip}$ & Frlm & Syrphidae & 289 & \\
\hline & $\mathrm{Fa} / \lg$ & Frlm & Syrphidae & 21 & \\
\hline & $\mathrm{Fa}$ & $\mathrm{Fr}$ & Vespoidea & 1 & \multirow[t]{2}{*}{ NS } \\
\hline & $\mathrm{Fa} / \lg$ & Frlm & Vespoidea & 1 & \\
\hline \multirow[t]{8}{*}{ Impatiens glandulifera } & $\lg$ & Im & Apoidea & 85 & \multirow[t]{2}{*}{$\lg \vee s \mathbf{I g} / \mathbf{F a}: X 2=93.36, p<0.001$} \\
\hline & $\lg / \mathrm{Fa}$ & Frlm & Apoidea & 35 & \\
\hline & $\lg$ & Im & Bombini & 836 & \multirow[t]{2}{*}{ Ig $\vee s$ Ig/Fa: $X 2=386.18, p<0.001$} \\
\hline & $\lg / \mathrm{Fa}$ & Frlm & Bombini & 1035 & \\
\hline & $\lg$ & Im & Syrphidae & 1 & \multirow[t]{2}{*}{ NS } \\
\hline & $\lg / \mathrm{Fa}$ & Frlm & Syrphidae & 3 & \\
\hline & $\lg$ & Im & Vespoidea & 11 & \multirow[t]{2}{*}{ NS } \\
\hline & $\lg / \mathrm{Fa}$ & Frlm & Vespoidea & 15 & \\
\hline \multirow[t]{4}{*}{ Impatiens parviflora } & Ip & Im & Apoidea & 4 & \multirow[t]{2}{*}{ NS } \\
\hline & $\mathrm{Ip} / \mathrm{Fa}$ & Frlm & Apoidea & 2 & \\
\hline & Ip & Im & Syrphidae & 234 & \multirow[t]{2}{*}{ Ip vs Ip/Fa: $X 2=106.09, p<0.001$} \\
\hline & $\mathrm{Ip} / \mathrm{Fa}$ & Frlm & Syrphidae & 179 & \\
\hline
\end{tabular}

Table 2 glmmADMB best-fit models for the revisits of flowers of Impatiens glandulifera by bumblebees in 2019 and 2020. Air temperature and pollinator species were included in the two models. The 2019 model included also cloud cover, while the 2020 model - the time of day, pollinator gender (male/female worker), area of flower profiles and interaction between the air temperature and pollinator gender

\begin{tabular}{lllll}
\hline Year & Effect & X2 & df & $\boldsymbol{p}$ \\
\hline 2019 & Temperature & 27.55 & 1 & $<0.001$ \\
& Pollinator & 28.67 & 2 & $<0.001$ \\
& Cloud cover & 5.72 & 2 & 0.057 \\
2020 & Temperature & 22.66 & 1 & $<0.001$ \\
& Day time & 3.01 & 2 & 0.2 \\
& Pollinator & 19.44 & 1 & $<0.001$ \\
& Gender & 48.7 & 1 & $<0.001$ \\
& Flower area & 5.22 & 1 & 0.02 \\
& Temperature*Gender & 34.9 & 1 & $<0.001$ \\
\hline
\end{tabular}

Fig. S2). Moreover, the number of revisits differed among the $B$. lucorum complex $(N=112)$, B. pascuorum $(N=$ $52)$ and $B$. terrestris $(N=43)$, with individuals of the former species revisiting the same flowers more frequently than the two latter species (differences at $p<0.001$; Fig. 3/2019). Interaction between temperature and pollinator species was nonsignificant in the model (Online Resource, Table S2).

In 2020, 9.7\% of the flowers were revisited (total $\mathrm{N}$ of visited flowers $=5679 ; \mathrm{N}$ flights $=484$ ), and during a single bumblebee flight, 515 flowers had 2 revisits (9.07\%), 33 had 3 revisits $(0.58 \%), 10$ had 1 revisit $(0.18 \%)$ and one had 5 revisits $(0.02 \%)$. We recorded the flights of 86 males (B. pascuorum), 394 female workers (348 B. pascuorum, 44 B. terrestris, 2 B. hypnorum) and 4 queens (3 B. hypnorum, 1 B. terrestris). The GLMM model with five fixed effects ('Temperature', 'Day time', 'Pollinator', 'Gender', 'Flower area'), one interaction ('Temperature*Gender') and one random factor ('Plant ID') was selected (Table S2). As in 2019 (Online Resource, Fig. S1), we confirmed that the revisits significantly increased with air temperature (Table 2). Moreover, in general, males 


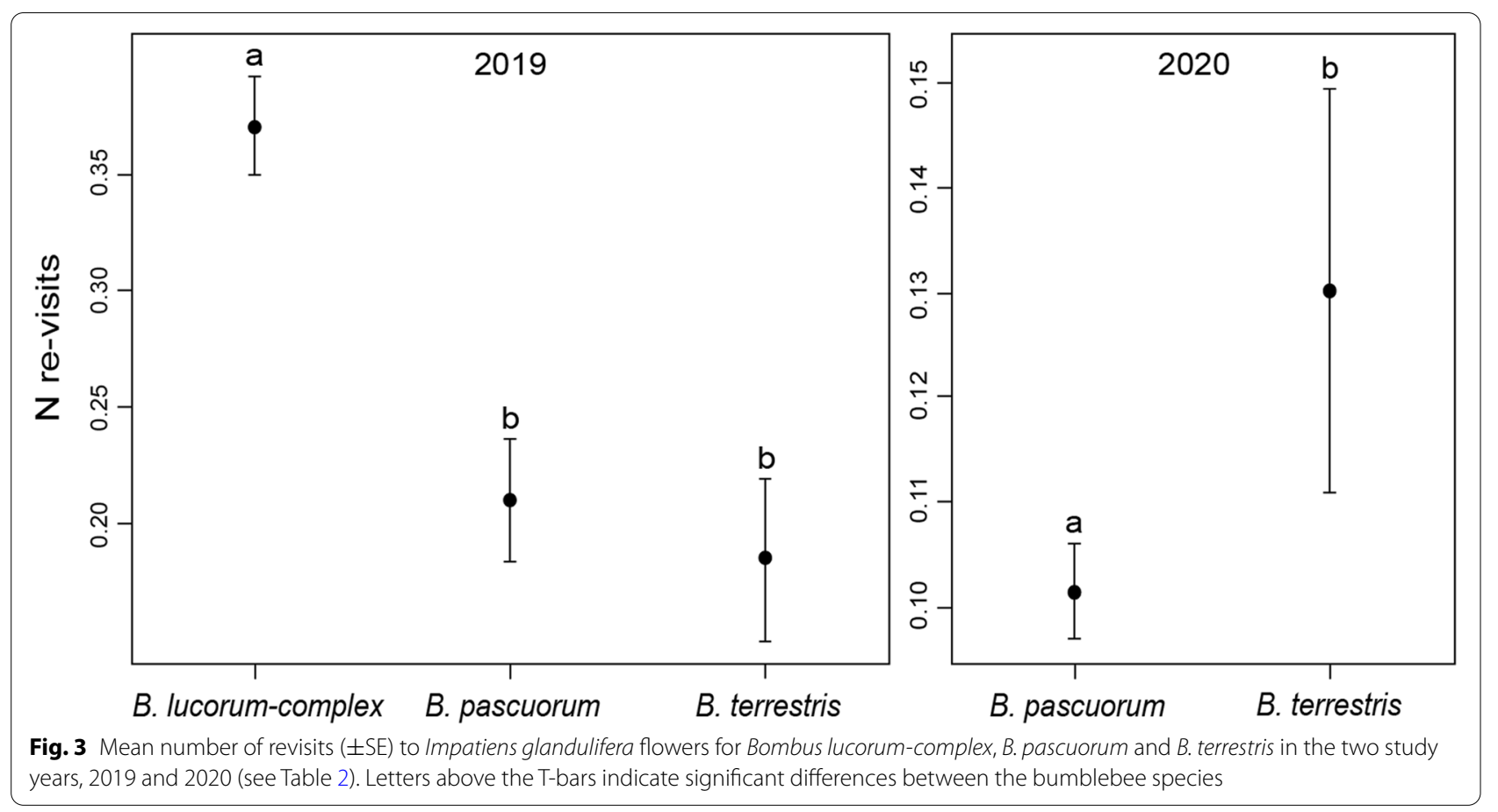

revisited flowers more frequently than female workers (Table 2). However, the interaction 'Temperature "Gender' revealed that at a very high temperature (exceeding $37^{\circ} \mathrm{C}$ ), males make fewer revisits than female workers (Table 2,
Fig. 4). At lower temperatures, the opposite trend was observed, with fewer revisits by female workers (Fig. 4). However, the only recorded male was $B$. pascuorum; thus, we were not able to check whether males of other

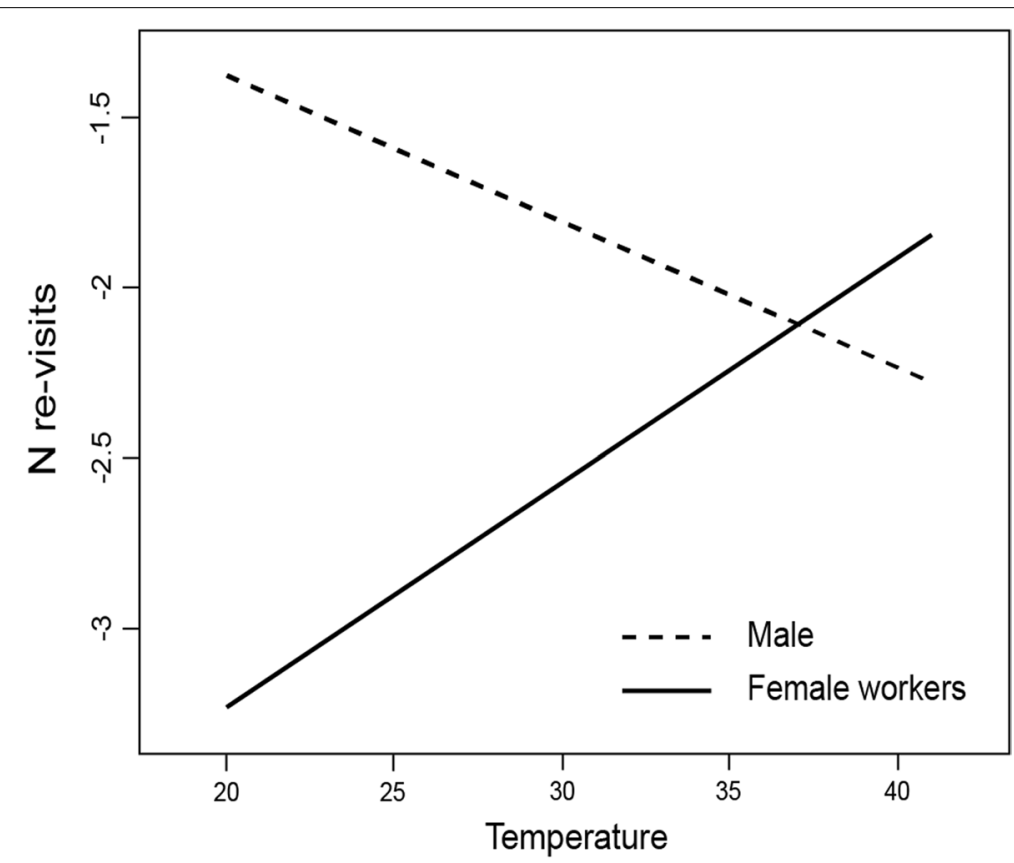

Fig. 4 Interaction plot between air temperature and pollinator gender (male/female worker) in the glmmADMB model with the estimated number of revisits of Impatiens glandulifera flowers as a target variable (see Table 2). The values on $y$-axis are in glmmADMB procedure default link-scale (log) 
species presented similar reactions to high temperatures. In turn, workers of $B$. hypnorum and all queens were too rare to be included in the results analysis. Between-species differences were also significant in that $B$. terrestris revisited the flowers more frequently than $B$. pascuorum (Table 2; Fig. 3/2020). The model also showed that larger flowers were revisited more often than smaller flowers (Table 2). Time of day, bumblebee size, sun radiation or the two interactions (temperature with pollinator species and temperature with pollinator size) were all nonsignificant in the model (Table 2; Online Resource, Table S2).

In 2020, we also tested factors that may determine which plants are most frequently chosen as the first to be visited. Stem height, size of flowers or their hue, were not important in this respect (Online Resource, Table S4); datasets on stem height and flower size of I. glandulifera individuals are included in Table S3 (Online Resource). Moreover, although GIS spatial analysis of the distribution of plants that were first to be visited in 2020 suggested that they were usually situated close to the plot edge (Online Resource, Fig. S3), the non-significant result for 'Location' variable in the GLM model did not supported this conclusion (Online Resource, Table S4).

\section{Discussion}

Invasive alien species decrease pollination of cultivated species

Impatiens glandulifera and I. parviflora are invasive alien species with a negative impact on nature conservation and human economies [15, 50, 51], while Fragaria $\times$ ananassa is a common, flavourful and healthy crop $[6,13]$. We revealed that the two alien species may compete with the cultivated species for pollinators. Previous studies $[8,9,11-14]$ demonstrated that the availability of pollinators determines the quality and volume of strawberry production. The results of our study, however, were obtained from cultivation plot experiments with a similar number of flowering plants per species. Their arrangement on the plot and the fact that there were approximately twice as many flowers in the variant in which alien and cultivated species were exposed together then in single-species variants, did not reflect real life conditions. These limitations may have synergistically affected the obtained results. It may be also important that the experimental Impatiens had significantly less flowers than wild-growing plants. For instance, experimental I. glandulifera had only 1-8 flowers per individual (average = $2, N=45$ ), while those from Kraków, Muszyna and Izerskie foothills had 4-138 flowers per individual (average $=34, N=90$; Najberek, unpubl. data). It suggests that under natural conditions the decrease in crop pollination can be significantly higher than it was demonstrated in this study. Thus, our outcomes should be verified using real-life strawberry crops with neighbouring Impatiens. Natural mosaics of crops and Impatiens patches may differ in area, density of individuals, with differing number of flowers and plant array, which may also play an important role in the studied plant-pollinator interactions. Real-life strawberry fields would allow assessment of the relevance of pollinator activity reduction on yield.

In the two study years, we demonstrated that the presence of the highly invasive alien I. glandulifera or less invasive I. parviflora decreased the number of pollinators that visited Fragaria $\times$ ananassa, with the most pronounced differences in the comparisons with I. glandulifera. This result is opposite to the assumption that the two Impatiens species may act as magnet species and enhance the pollination of strawberries. The GLMM showed that the overall number of pollinators of Fragaria $\times$ ananassa decreased when I. glandulifera was present, and the proportion tests indicated that the taxa associated with this decrease were Bombini and Syrphidae. The former group rarely visited Fragaria $\times$ ananassa; however, hoverflies were the main pollinators of this crop in our study.

In the comparison between Fragaria $\times$ ananassa and the less invasive alien I. parviflora, the GLMM model did not reveal any differences. However, the proportion tests indicated that Apoidea, Bombini and Syrphidae significantly decreased on Fragaria $\times$ ananassa when I. parviflora was present. This finding suggests that I. parviflora may decrease pollination of strawberry, which is similar to that observed for I. glandulifera.

Interestingly, the number of Apoidea recorded from $I$. glandulifera was higher in tests conducted solely for this species than when it was exposed on the plot with Fragaria $\times$ ananassa. A similar situation was noted in the case of Syrphidae of I. parviflora. These results indicate that alien species may also be negatively affected when they co-occur with strawberry crops. The impact of the decrease in Apoidea on I. glandulifera was probably negligible because in our plot, it was pollinated mainly by bumblebees. However, it potentially would play a more significant role in areas where bees constitute the dominant pollinator group. In turn, Syrphidae are the main pollinators of I. parviflora [21-23], and their absence may reduce the spread of this plant. A high number of flowers in a habitat patch has been found to positively influence the number of hoverflies [52]. Although the combination of $I$. parviflora and Fragaria $\times$ ananassa provided at least twice as many flowers as each of the single plant species variants, the number of Syrphidae decreased. Therefore, some other factors (stronger than flower abundance) impeded the presence of Syrphidae in our experiment. I. parviflora individuals were twice as tall as Fragaria $\times$ ananassa individuals; thus, flowers 
of the former species were more available than the flowers of the latter. Hoverflies adjust their flight altitude to be optimal to detect pollen and nectar based on optical and olfactory cues [53], and the co-occurrence of the two species that significantly vary in height may be confusing for hoverflies. In addition, I. parviflora and Fragaria $\times$ ananassa differ in terms of flower size, and these characteristics may also determine the flight altitude [48]. Flowers of the latter species are larger and could be detected earlier and at higher altitudes. It should also be noted that the presented tests were conducted using an experimental design that included the random arrangement of strawberries and the two balsam species in plots in very close proximity to each other. This dependence could be modified to test real-life crop fields and neighbouring alien plant patches. The impact of alien species should be stronger in close proximity to the field and weaker in more distant plots. However, further tests are needed to confirm this assumption.

The dependence between flight altitude and plant height should also be considered regarding the results of the GLMM analysis. The model revealed that taller plants are more frequently pollinated than shorter plants. The tallest species included in the study was I. glandulifera, which is very attractive to pollinators [15]. However, the attractiveness of I. glandulifera did not play a only role because individuals of this species were also very diverse in terms of their height $(65-182 \mathrm{~cm})$. This result, therefore, also demonstrates that pollinators detect flowers of taller plants quicker than flowers of shorter plants. Moreover, in the context of biological invasions, it can be assumed that tall alien plants, including the highly invasive alien I. glandulifera [15], may be very effective in decreasing pollination of native plants.

We experimentally demonstrated that alien plants may decrease the pollination of crops. Although not directly tested during the present study, it was proved that lower pollination by insects usually negatively affects crop production [e.g., 14, 54]. A practical implication is that alien plant species that have common pollinators with a given crop and occur in close proximity to the cultivation area should be controlled. This pertains not only to I. glandulifera but also to many other alien plants attractive for pollinators (e.g., I. capensis, I. balfourii, Asclepias syriaca, Solidago gigantea, S. canadensis, Reynoutria japonica, Spiraea tomentosa). Although the ability of these alien species to tempt pollinators away from crops has not been directly tested, their control is recommended near crops.

A buffer zone in which to undertake control measures should be individually set out for particular crop types according to the migration capability of their pollinators. For example, tomatoes, cucumbers, muskmelons, watermelons, raspberries, black currant, lavender, bilberry, cherry trees, peach trees or apricot trees are pollinated by bumblebees that can collect nectar and pollen from preferred food sources situated as far as $1500 \mathrm{~m}$ away from their colonies [55]. Therefore, alien plants should optimally be controlled within a $1500 \mathrm{~m}$ buffer from those crops. On the other hand, the migration capabilities of Syrphidae are more limited than those of bumblebees and can cover distances up to $200 \mathrm{~m}$ from the food source [53]. Therefore, a $200 \mathrm{~m}$ control buffer around Fragaria $\times$ ananassa crops seems appropriate. In addition, it should be also noted that the localities of wild-growing I. parviflora and I. glandulifera occurred 400 and 4700 meters, respectively, from the cultivation plot. Considering the migration capability of hoverflies, bumblebees and bees $[53,55,56]$ those localities did not influence the obtained results.

\section{Revisiting of flowers increases with air temperature}

Bumblebees secrete a mixture of hydrocarbons from their leg tendon glands [30] that can be recognized by themselves as well as their siblings and conspecifics during foraging flights [25-29]. The efficiency of nectar feeding of colony conspecifics is mostly affected by flower choices; therefore, revisits to probed flowers may have negative consequences for the colony economy as well as for the pollination rate of host plants [24]. In our 2-year study, revisits and flower choice were studied for three bumblebee species, Bombus pascuorum, B. lucorum complex, B. terrestris, and an alien plant, Impatiens glandulifera, which is known to produce high amounts of nectar. Interestingly, we found that the number of revisits increased with the air temperature. It is known that climate warming may lead to morphological, physiological and functional mismatches between plants and pollinators $[35-39,57-60]$ as well as to a lower availability of food plants [61-63]. The negative impact of increasing temperature on the effectiveness of scent marking, however, has only been studied occasionally and not in the context of plant-pollinator interactions [40, 41].

The increase in the number of revisits with air temperature was particularly significant for female workers. In general, female B. pascuorum, B. lucorum-complex, and $B$. terrestris revisited probed flowers less frequently than males (B. pascuorum). However, at very high temperatures $\left(>37^{\circ} \mathrm{C}\right)$, the opposite result was observed, with more revisits by female workers. These trends may be associated with differences in the composition of cuticular hydrocarbons ( $\mathrm{CHCs}$ ) secreted by bumblebees between males and females. Males secrete significantly more compounds with longer chain lengths (identified as 'wax esters') than female workers and queens [30]. At the same time, $\mathrm{CHCs}$ with longer-chain compounds 
have higher melting temperatures and insects equipped with such a waxy layer efficiently manage water $[64,65]$. Therefore, it can be assumed that the body of bumblebee males is better protected against extremely high temperatures, and these better conditions of males may, in turn, result in a lower number of errors in flower choice. Another role of $\mathrm{CHCs}$ is to facilitate communication between insects by conveying various types of information $[64,65]$. For example, it is known that $\mathrm{CHC}$ male compounds allow them to mark a flight route to attract virgin queens. We assume that scent marks created using longer-chain wax esters also have other functions and may be more durable at hot temperatures than scent marks secreted by female workers. This presumption is worthy of experimental testing in the future.

However, it should be stressed that we did not assess the nectar content in the visited flowers because the assumption was that bumblebees would avoid previously probed and scent-marked flowers during a single flight regardless of the production potential of the plant. Moreover, it is well known that I. glandulifera produces significantly more nectar than Fragaria $\times$ ananassa $[15$, 19]. A disadvantage of this approach was that we did not test whether nectar replenishment in probed flowers may occur during a single foraging flight. Previous studies demonstrated that replenishment occurs rapidly, i.e., within minutes [31]. For instance, replenishment was found to occur within 3 minutes based on pollinator sounds [32]. In the present study, a single bumblebee flight took only approximately 45 seconds, whereas the number of re-visits per single flight was between 1 and 5. However, as I. glandulifera is the best nectar rewarding plant species in Europe [15], it cannot be excluded that nectar replenishment occurs more rapidly, i.e., within seconds. If I. glandulifera was capable of such remarkably fast replenishment, then the meaning of the recorded revisits during the tests would be changed. Such changes would mean that at very high temperatures, workers can better recognize nectar-replenished flowers than males, and it would also mean that males are more efficient at temperatures below $37^{\circ} \mathrm{C}$. If this supposition holds true, then the role of males in colony success could be even higher than that under the assumption that revisits are erroneous choices. Nevertheless, further studies on bumblebee revisits to Himalayan balsam are needed to provide further insights.

A previous study [48] demonstrated that large flowers are easier to find for bumblebees, which reduces the flight time. In contrast, we found that the number of revisits increased with the flower size. Larger flowers produce higher volumes of nectar than smaller flowers [66]; therefore, more intensive olfactory cues of larger flowers may impede the recognition of scent-marks secreted by bumblebees. It is likely that such cues could play an important role in the case of nectar-rich flowers of I. glandulifera; however, neither nectar volume nor sugar concentration were assessed in this study. Thus, this aspect needs to be better investigated, and our results should be considered with due caution.

In Experiment 2, we also indicated I. glandulifera individuals that likely were the first to be visited by newly arriving bumblebees. The graphical GIS analysis of the arrangement of surveyed plants in particular surveys suggested that the plants close to the edge of the plot, were most likely to be detected first. Interestingly, previous studies demonstrated that higher diversity and numbers of Syrphidae pollinators were recorded in field margins than in within-crop wildflower patches, despite the lower flower density in the former patches [52]. This finding was explained by the fact that field margins may offer additional rewards other than pollen and nectar availability (such as a high abundance of aphids for aphidpredatory insects) [52]. However, our finding was not supported by the GLM results in any respect. The stem height, flower size, flower hue also did not play a role in this analysis. It should, however, be noted that our study was conducted at experimental plot, thus it cannot be excluded that in real-life strawberry field tests the results would be more pronounced.

\section{Conclusions}

Alien plant species are often distributed in close proximity to cultivation fields; however, their influence on crop yields has not been experimentally tested to date. In the present study, we demonstrated that two invasive alien species, I. glandulifera and I. parviflora, may decrease pollination of strawberry, Fragaria $\times$ ananassa. The results were obtained under experimental conditions that included a similar number of flowering plants per species and a random plant arrangement, although they did not include real distances between the crop and patches of alien balsams, and real number of flowers per species that are available for pollinators in natural conditions. Therefore, further tests in real-life strawberry fields and neighbouring patches of balsams are recommended to confirm that reduction in pollinator activity on strawberries is actually relevant.

Flower choice decisions may have consequences for both pollinating bumblebees and the plants that attract them. In this study, we revealed that the revisits of probed flowers of I. glandulifera by bumblebee workers increase with the air temperature. However, it is necessary to investigate whether revisits are errors in flower choice or determined by very fast nectar replenishment in I. glandulifera flowers. The first scenario would be alarming in terms of global warming because female workers provide 
food for larvae, while the second scenario would indicate the higher foraging efficiency of bumblebee workers than males under very high temperatures $\left(>37^{\circ} \mathrm{C}\right)$.

We also found that the importance of effectively feeding male bumblebees for colony success may be even higher than usually expected [67]. Although bumblebee males do not feed larvae, they participate in pupal incubation [68], and the traits of males (e.g., sperm length and quality) determine queen survival during winter as well as their longevity and reproductive success $[69,70]$. If revisits of I. glandulifera flowers are errors in flower choice, then in very hot weather $\left(>37^{\circ} \mathrm{C}\right)$, males may be more efficient in foraging than female workers. On the other hand, if revisiting of probed flowers is beneficial in terms of the amount of nectar replenishment, then the role of males in a colony could be even higher; thus, at temperatures below $37^{\circ} \mathrm{C}$, males will be more efficient in recognizing refilled flowers than female workers. Nevertheless, further studies are needed to verify this supposition.

\section{Methods}

The two experiments were carried out under common garden conditions in a cultivation plot of the Institute of Nature Conservation Polish Academy of Sciences in Cracow (S Poland; plot area $=2.7$ ares) using seedlings of $I$. glandulifera and I. parviflora transplanted from neighbouring localities. A total of 100 seedlings were used for each species, with 25 seedlings per locality. The localities for I. glandulifera were Marcyporęba (forest edge), Zelczyna (roadside), Tyniec (riverside) and Szczyglice (riverside), and those for I. parviflora were Wielkie Drogi (forest), Kraków Młynówka Królewska (green area), Kraków Rząska (forest) and Dolina Brzoskwinki (forest edge). The former species was tested in 2019 and 2020, while the latter was tested in 2020. The use of plant parts in the present study complies with international, national and institutional guidelines. In both study years, all necessary permissions were obtained for I. glandulifera transplantation from the wild and cultivation (permission no.: OP-I.672.2.2019.KW.2, OP-1.672.6.2020. KW) and for disturbing protected bumblebees (permission no.: OP-I.6401.97.2019.KW.2, OP-I.6401.111.2020.MKI).

Two-year-old cold-stored $\left(\right.$ at $\left.-2^{\circ} \mathrm{C}\right)$ frigo seedlings $(N$ $=104)$ of Fragaria $\times$ ananassa "Vibrant" (early variety) were purchased in July 2019 from a strawberry farm located ca. $30 \mathrm{~km}$ away from the cultivation plot. Commercial strawberries are commonly offered as cold-stored plants because they provide fresh fruits for autumn harvesting. The use of frigo seedlings in the experiments allowed for the testing of competition for pollinators by I. glandulifera because the flowering time of both plants overlapped. In Poland, flowering of I. glandulifera occurs from July to October, while the flowering of frigo strawberries could be regulated. Frigo seedlings are usually planted from mid-May to mid-July. In the experiment, planting was carried out on 11 July, and the flowering phase started 3 weeks later. In turn, the first flowers of I. glandulifera were recorded on 15 July. The last flowers of frigo strawberries were noted in early September, and the last survey was conducted on 30 August. The end date of I. glandulifera flowering was not estimated because the tested plants were eradicated after the end of the experiment.

In 2020, the same (three years old) individuals of Fragaria $\times$ ananassa were tested together with I. parviflora. Cold storage of seedlings was not necessary because the flowering time of both species naturally overlapped in June. In our experiment, the strawberries flowered between 10 June and 8 July. In turn, I. parviflora started this phase on 5 June, and as in the case of I. glandulifera, the plants were eradicated after the end of the experiment; in Poland, the species ended flowering in September.

The seedlings of the three studied species were cultivated in garden pots (1.1 L capacity) filled with universal garden soil mixed with sand $[71,72]$. Following the methods of cultivation of Fragaria $\times$ ananassa, the substrate was additionally enriched with a fertilizer. Moreover, to protect the seedlings from Iberian slugs (Arion lusitanicus), the pots were wrapped with copper sticky tape. In 2019, young seedlings of I. glandulifera were under a high pressure exerted by this slug and nearly half of $I$. glandulifera seedlings were entirely eaten during the 10 first days of cultivation and needed to be replaced with new seedlings. It should be also noted that the eaten seedlings were short, while taller seedlings were browsed only occasionally. Although the slugs did not attack I. parviflora or Fragaria $\times$ ananassa, the copper sticky tape was used in all pots, regardless of plant species, completely eliminating the impact of slugs.

Individuals of two invasive alien Impatiens species and cultivated Fragaria $\times$ ananassa were used in two different experiments.

\section{Experiment 1: Invasive alien species decrease pollination of cultivated species}

The aim of Experiment 1 was to check whether the alien Impatiens decrease pollination of cultivated strawberries. As pollinators, we define all insects visiting flowers to collect pollen or nectar and may carry pollen from the male to female flower phase (from anther to stigma).

In August 2019, Fragaria $\times$ ananassa was exposed together with the highly invasive alien I. glandulifera, while in June 2020, Fragaria $\times$ ananassa was exposed together with the less invasive I. parviflora. The former tests were performed on 10 study days (dates: 5-10.08, 
$12.08,26-27.08,30.08)$, while the latter were performed on 9 study days (dates: 17-19.06, 22-26.06, 29.06). Each study day pollinator activity was assessed in three variants. In "Impatiens species" variant (Im), only individuals of the alien species were exposed (I. glandulifera or I. parviflora); in "Fragaria $\times$ ananassa" variant $(\mathrm{Fr})$, only individuals of the cultivated species were exposed, while in "Fragaria $\times$ ananassa AND Impatiens species" variant (FrIm), individuals of one of the two alien species were arranged together with the cultivated ones. Each study day, the sequence of the three variants, as well as the arrangement of particular plant individuals on the plot, were randomly selected. In the Im variant, the individuals of Fragaria $\times$ ananassa were removed from the plot and closed indoors, while in $\mathrm{Fr}$, the same procedure was applied for the Impatiens individuals. A similar number of randomly selected flowering plants per species ( 30 of 100 transplanted plants) was included on each study day (the redundant flowering plants were closed indoors).

Each study day, the tests started in the morning (between 9:00 $\mathrm{h}$ and 11:00 h) and ended in the afternoon (between 13:30 $\mathrm{h}$ and 15:30 h). In each variant, the number of pollinators visiting the surveyed plants was counted over a 70 -minute period. There were 30 -minute breaks between the variants to ensure that pollinators recognized the change in plant species availability on the plot. In total, each study day, the observation time took 210 minutes with 60 -minute breaks.

Flights of the pollinators were tracked, and ID numbers of subsequently visited plants were noted. The recorded pollinators were not caught but identified while pollinating. It should also be noted that Formicidae (Online Resource, Table S2) were not included in the analysis because they are considered to be nectar thieves rather than beneficial visitors of flowers, and their activity damages flowers and results in a significant reduction in seed set $[73,74]$.

The surveys were conducted in warm and windless weather. For each day and each variant, the sampling effort was similar, with the same observation time and the same researcher tracking the pollinator flights. Each study day, the number of flowers per plant was counted and the air temperature was measured using data loggers i-Button DS1921G (with 10 minute intervals). During the last survey, the height of the plants was also measured (Online Resource, Table S3).

\section{Experiment 2: Revisiting flowers increases with air temperature}

In 2019, we also checked whether bumblebees were revisiting the same individual flowers of I. glandulifera that they had previously visited during the same flight and tested the factors that may determine such revisits
(10 study days; dates: 5-10.08, 12.08, 26-27.08, 30.08); notably, the same I. glandulifera individuals were used as in Experiment 1. The assumption was that during a single flight, bumblebees would avoid flowers that were already probed and scent-marked, regardless of the nectar production potential of the plant; therefore, we did not assess the nectar content in the visited flowers. In 2019, we found that the number of revisits increased with temperature; therefore, in the next study year, we arranged a new experiment dedicated to testing bumblebee revisits under high air temperatures exceeding $>30^{\circ} \mathrm{C}$. The high temperature level was estimated following the Climate of Poland 2020 report [75].

In 2020, the surveys were conducted exclusively in hot weather with air temperatures exceeding $30^{\circ} \mathrm{C}$ (10 study days; dates: 07-09.08, 11-14.08, 17.08, 20-21.08). As in 2019, the assessment was conducted solely with I. glandulifera individuals $(\mathrm{N}=100)$ and their bumblebee pollinators. Likewise, in 2019, bumblebees were not caught, the assessment was carried out during their activity at flowers, and all individuals were identified to the species level. To check whether bumblebee revisits are determined by high temperature or more associated with diurnal changes in pollinator activity, we carried out surveys three times a day: in the morning (between $8: 30 \mathrm{~h}$ and 10:30 h), at noon (between 11:30 $\mathrm{h}$ and 13:30 h) and in the afternoon (between 16:30 $\mathrm{h}$ and 18:30 h). Each survey, regardless of the time of day, took 70 minutes $(210$ minutes per study day). The average recorded temperatures were $28.4^{\circ} \mathrm{C}$ in the morning, $35.2{ }^{\circ} \mathrm{C}$ at noon and $27.3^{\circ} \mathrm{C}$ in the afternoon. To facilitate the quantification of revisits, before each survey in 2020, all but one representative flower per I. glandulifera was cut off.

Each recorded bumblebee was identified in terms of its gender/family caste (in the case of females), and its size was roughly assessed (small, average, big). The average number of flowers visited by each bumblebee individual was 9 (range: 5-32). It was estimated that a single visit to a flower took about 5 seconds; thus, each flight was monitored for approximately 45 seconds. Although bumblebee queens and female workers of B. hypnorum were noted in the study $(\mathrm{N}=4$ and $\mathrm{N}=2$, respectively), they were excluded from the analysis because of their numbers were too low. The temperature was measured using data loggers (with 10 minute intervals). Moreover, using a hand-held environmental metre (Extech $45170 \mathrm{CM}$ ), sun illuminance was noted (in 35 minute intervals). Revisits of flowers may also be determined by flower size; in 2020, the area of flowers was measured using 4 flowers randomly selected per surveyed plant, which were cut off during the two last surveys, and their profiles were photographed against a millimetre paper background (Canon EOS 60D, Canon EF $100 \mathrm{~mm} \mathrm{f/2.8} \mathrm{Macro} \mathrm{USM} \mathrm{lens} \mathrm{and}$ 
ring flashlight). Digital images (Online Resource, Fig. S4) were analysed with ImageJ software (ver. $1.51 \mathrm{k}$ ). The area of one flower side was assessed (Online Resource, Table S3), which corresponded to half of the total flower area. Moreover, in 2020, we also assessed which I. glandulifera individuals were the first to be selected by arriving bumblebees, and we identified which flower traits determined this choice. Each year, the sampling effort during the surveys was similar, with the same observation time and the same researcher tracking the pollinator flights.

\section{Statistical analyses}

The data were analysed with generalized linear mixed models (GLMMs) and general linear models (GLMs). The models with the lowest Akaike information (AIC) criterion (Online Resource, Table S2) were chosen [76]. Pairwise contrasts were applied for between-group comparisons.

In Experiment 1 ("Invasive alien species decrease pollination of cultivated species"), statistical analyses were carried out using SPSS ver. 26.0 [77]. The GLMM model for the analysis assumed a Poisson distribution of the number of recorded pollinators per plant individual per survey ('N pollinators') as a target variable (sample size $=1422$ ). The base model (with all variables) included 4 fixed effects and two random factors (Online Resource, Table S2). Variants (Im, Fr, FrIm) and plant species (I. glandulifera, I. parviflora, Fragaria $\times$ ananassa) were combined into a single variable ('Variant and species'), which allowed for between-species comparisons for variant FrIm, in which alien and cultivated species were exposed together. The stem height ('Stem height') and number of flowers (' $\mathrm{N}$ flowers') were added to the model because the three species significantly differed in these parameters (e.g., I. glandulifera had more flowers than the two other species and Fragaria $\times$ ananassa was very short). Although weather conditions during the surveys were consistent (warm and windless), the air temperature increased as the day progressed. Therefore, the temperature variable ('Temperature'), which is important for pollinator activity, was also included in the model. In addition, to account for potential variation in the tested factors throughout the day, sequence of the three variants (Im, Fr, FrIm), in which pollinator activity was assessed, was assigned as 'Time intervals' (1st, 2nd, and 3rd) and added to the model as a random factor. Moreover, the unique ID number was assigned to each surveyed plant individual. As the number of visits per particular plant individual was different, 'Plant ID' was also added as a random factor. For each arrangement variant, the recorded pollinators were assigned to four broad taxa (Bombini, Syrphidae, Apoidea and Vespoidea).
Differences between taxon groups recorded in $\mathrm{Im}, \mathrm{Fr}$ and FrIm variants were tested separately for each plant species using Tests of Equal or Given Proportions ("proportion tests"), and the statistical analysis was carried out using R [78].

In Experiment 2 ("Revisiting of flowers increases with air temperature"), statistical analyses were carried out using R [78]. Two separate base GLMM models (with all variables) were used for each study year (Online Resource, Tables S2). The target variable, i.e., the number of revisits per flower per pollinator ('N revisits'), was similar in both models. Because no revisits (value 0) occurred in most cases $(75.6 \%$ and $90.3 \%$ of records in 2019 and 2020 , respectively; zero-inflation parameter in both years $<0.05)$, the target variable was tested using AD Model Builder with a zero inflation parameter and a negative binomial distribution (the glmmADMB package) [79]. In the model for 2019 (sample size $=1435$ ), the fixed effects were air temperature ('Temperature'), bumblebee species ('Pollinator'), and cloud cover (cloudy, sunny or partially sunny; 'Cloud cover'). Because different bumblebee species have different tolerances to temperature (darker species are more sensitive to high temperatures), the interaction between air temperature and species was also included in the model. Moreover, the number of pollinator visits was different for individual plants; therefore, we added 'Plant ID' as a random effect (Online Resource, Table S2). In 2020, more variables and interactions were included in the model and the sample size was larger $(N$ $=5639$ ). The air temperature, pollinator species and ID number of plants as random effects were consistent with those used in 2019; however, cloud cover was replaced by sun illuminance measurements ('Sun radiation'). New variables were also included: gender/family caste (male/ female worker; 'Gender') of pollinators, their approximated size ('Size'), time of the survey ('Day time') and area of flower profiles ('Flower area'; Online Resource, Fig. S4). The interaction 'Temperature*Pollinator' was also included in the model. As the effect of temperature may interact with gender/caste or bumblebee size, 'Temperature"Gender' and 'Temperature*Size' were also included.

To test which individuals of I. glandulifera are the first to be selected by arriving bumblebees, the number of first visits in particular surveys was counted for each individual plant and used as a target variable (' $\mathrm{N}$ first visits') in the GLM model with a Poisson distribution $($ sample size $=244$; Online Resource, Table S4). Four individuals who were never the first to be visited were also included in the model. Moreover, four fixed effects were included: 'Stem height', 'Flower area, 'Flower hue' and 'Location'. Flower hue, that plays a significant role in pollination by animals [80], was included because 
particular individuals of I. glandulifera differed in this respect, having light (pinkish) or dark (reddish) flowers. We also added a binary variable - location - that allowed to test whether individuals from the plot margins were more frequently first visited than plants situated in central parts of the plot. ArcGIS geographic information system was used to graphically visualize the first visited plants (Online Resource, Fig. S3).

\section{Supplementary Information}

The online version contains supplementary material available at https://doi. org/10.1186/s12870-021-03282-1.

Additional file 1: Table S1. Pollinators recorded from flowers of cultivated Fragaria $\times$ ananassa, highly invasive alien Impatiens glandulifera and invasive alien species I. parviflora in Experiment 1. The table also includes Formicidae, which is known to include nectar thieves. Table S2. Base, candidate and best-fit models in Experiments 1 and 2. The selected best-fit model (bolded) had the lowest corrected Akaike information value AICc. Table S3. Stem height of individuals of cultivated Fragaria $\times$ ananassa, highly invasive alien Impatiens glandulifera and invasive alien species I. parviflora. Data on the profile area of flowers of I. glandulifera (see Fig. S4) are also included. Table S4. GLM model testing factors correlated with an Impatiens glandulifera individual being the first to be chosen by visiting bumblebees. The number of first choices for each plant was a target variable, while the stem height, flower size, flower hue and location were fixed effects. Figure S1. Effect of air temperature on the estimated number of revisits of flowers of Impatiens glandulifera by bumblebees (Bombus lucorum complex, B. pascuorum and B. terrestris). Figure S2. Effect of cloudy cover on the mean number of revisits ( $\pm \mathrm{SE}$ ) of flowers of Impatiens glandulifera by bumblebees (Bombus lucorum complex, B. pascuorum and B. terrestris). Figure S3. Spatial array of Impatiens glandulifera individuals chosen by bumblebees as first to be visited. In each survey (S1-S10), the total number of first visits per particular plant is demonstrated using a colour scale. Figure S4. Profile of the Impatiens glandulifera flower against a millimetre paper.

\section{Acknowledgements}

We thank Witold Gorajczyk (the owner of the 'Truskawka Sułoszowa'strawberry farm) for strawberry seedlings and for his advice on their cultivation.

\section{Authors' contributions}

Original research idea: KN; Study design: KN, WS; Surveys and pollinators identification: KN, AK; Statistical analyzes: KN; Writing - original draft preparation: KN; Writing - review and editing: KN, WS, AK; Funding acquisition: KN. All authors have read and approved the manuscript.

\section{Funding}

This work was supported by the Institute of Nature Conservation, Polish Academy of Sciences (Cracow, Poland), through grant funding for young scientists. The funder had role in data collection.

\section{Availability of data and materials}

The data generated or analyzed during the current study are included in this published article and its supplemental data files and available from the corresponding author on reasonable request.

\section{Declarations}

\section{Ethics approval and consent to participate}

All animal and plant experiments were approved by the Regional Directorate for Environmental Protection, references numbers: OP-I.672.2.2019.KW.2, OP-I.672.6.2020.KW, OP-I.6401.97.2019.KW.2, OP-I.6401.111.2020.MKI.
Consent for publication

Not applicable.

\section{Competing interests}

The authors declare that they have no conflict of interest.

Received: 17 May 2021 Accepted: 20 October 2021

Published online: 30 October 2021

References

1. Klein A-M, Vaissière BE, Cane JH, Steffan-Dewenter I, Cunningham SA, Kremen C, et al. Importance of pollinators in changing landscapes for world crops. Proc R Soc B Biol Sci. 2007;274:303-13.

2. Garibaldi LA, Steffan-Dewenter I, Winfree R, Aizen MA, Bommarco R, Cunningham SA, et al. Wild pollinators enhance fruit set of crops regardless of honey bee abundance. Science. 2013;339:1608-11.

3. Garibaldi LA, Carvalheiro LG, Leonhardt SD, Aizen MA, Blaauw BR, Isaacs R, et al. From research to action: enhancing crop yield through wild pollinators. Front Ecol Environ. 2014;12:439-47.

4. Nichols RN, Goulson D, Holland JM. The best wildflowers for wild bees. J Insect Conserv. 2019;23:819-30.

5. Lieten P. Strawberry production in Central Europe. Int J Fruit Sci. 2005;5:91-105

6. Agarwal P, Wang Y, Holland T, Bennett D, Morris M. Strawberry consumption associated with reduced alzheimer's dementia risk (FS05-06-19). Curr Dev Nutr. 2019;3:nzz052.FS05-06-19:1.

7. Abrol DP, Gorka AK, Ansari MJ, Al-Ghamdi A, Al-Kahtani S. Impact of insect pollinators on yield and fruit quality of strawberry. Saudi J Biol Sci. 2019;26:524-30.

8. Chagnon M, Gingras J, DeOliveira D. Complementary aspects of strawberry pollination by honey and IndigenQus Bees (Hymenoptera). J Econ Entomol. 1993;86:416-20.

9. Dimou M, Taraza S, Thrasyvoulou A, Vasilakakis M. Effect of bumble bee pollination on greenhouse strawberry production. J Apic Res. 2008;47:99-101.

10. Nitsch JP. Growth and morphogenesis of the strawberry as related to auxin. Am J Bot. 1950;37:211-5.

11. Free JB. The foraging behaviour of honeybees (Apis mellifera) and Bumblebees (Bombus Spp.) on Blackcurrant (Ribes nigrum), Raspberry (Rubus idaeus) and Strawberry (Fragaria x Ananassa) Flowers. J Appl Ecol. 1968;5:157

12. Pion S, de Oliveira D, Paradis R. Pollination agents and productivity of strawberries "Redcoat", Fragaria X ananassa Duch. Phytoprotection. 1980;61:72-8

13. Paydas S, Eti S, Kaftanoglu O, Yasa E, Derin K. Effects of pollination of strawberries grown in plastic greenhouses by honeybees and bumblebees on the yield and quality of the fruits. Acta Hortic. 1998;513:443-52.

14. Paydas S, Eti S, Sevinç S, Yasa E, Derin K, Kaska N, et al. Effects of different pollinators to the yield and quality of strawberries. Acta Hortic. 2000;522:209-18.

15. Chittka L, Schürkens S. Successful invasion of a floral market. Nature. 2001;411:653.

16. Charlebois JA, Sargent RD. No consistent pollinator-mediated impacts of alien plants on natives. Ecol Lett. 2017;20:1479-90.

17. Woo K, Choo H, Choi K. Studies on the ecology and utilization of pollinating insects. Korean J Apic. 1986;1:54-61.

18. Ugoletti P, Stout JC, Jones MB. Ecophysiological traits of invasive and non-invasive introduced Impatiens species. Biol Environ Proc R Ir Acad. 2011;111B:143-56.

19. Titze A. The efficiency of insect pollination of the neophyte Impatiens glandulifera (Balsaminaceae). Nord J Bot. 2000;20:33-42.

20. Vervoort A, Cawoy V, Jacquemart A-L. Comparative reproductive biology in co-occurring invasive and native Impatiens species. Int J Plant Sci. 2011;172:366-77.

21. Chmura D. Biology and ecology of an invasion of Impatiens parviflora DC in natural and semi-natural habitats. Bielsko-Biała: Akademia TechnicznoHumanistyczna; 2014.

22. Csiszár Á, Bartha D. SMALL BALSAM (Impatiens parviflora DC.). In: Botta-Dukát Z, Balogh L, editors. The most important invasive plants in 
Hungary. Budapest: Institute of Ecology and Botany, Hungarian Academy of Sciences; 2008. p. 139-49.

23. Schmitz G. Impatiens parviflora D.C. (Balsaminaceae) als Neophyt in mitteleuropäischen Wäldern und Forsten - eine biozönologische analyse. Z Für Ökol Naturschutz. 1999;7:193-206.

24. Leonard AS, Dornhaus A, Papaj DR. Why are floral signals complex? An outline of functional hypotheses. In: Patiny S, editor. Evolution of plantpollinator relationships. Cambridge: Cambridge University Press; 2011. p. 279-300. https://doi.org/10.1017/CBO9781139014113.010.

25. Goulson D, Hawson SA, Stout JC. Foraging bumblebees avoid flowers already visited by conspecifics or by other bumblebee species. Anim Behav. 1998;55:199-206.

26. Pearce RF, Giuggioli L, Rands SA. Bumblebees can discriminate between scent-marks deposited by conspecifics. Sci Rep. 2017;7:43872.

27. Saleh N, Ohashi K, Thomson JD, Chittka L. Facultative use of the repellent scent mark in foraging bumblebees: complex versus simple flowers. Anim Behav. 2006;71:847-54.

28. Schmitt U, Bertsch A. Do foraging bumblebees scent-mark food sources and does it matter? Oecologia. 1990;82:137-44.

29. Schmitt U, Lübke G, Francke W. Tarsal secretion marks food sources in bumblebees (Hymenoptera: Apidae). Chemoecology. 1991;2:35-40.

30. Jarau S, Žáček P, Šobotník J, Vrkoslav V, Hadravová R, Coppée A, et al. Leg tendon glands in male bumblebees (Bombus terrestris): structure, secretion chemistry, and possible functions. Naturwissenschaften Sci Nat. 2012;99:1039-49.

31. Luo EY, Ogilvie JE, Thompson JD. Stimulation of flower nectar replenishment by removal: a survey of eleven animal-pollinated plant species. J Pollinat Ecol. 2014;12:52-62. https://doi.org/10.26786/1920-7603(2014)2.

32. Veits M, Khait I, Obolski U, Zinger E, Boonman A, Goldshtein A, et al. Flowers respond to pollinator sound within minutes by increasing nectar sugar concentration. Ecol Lett. 2019;22:1483-92.

33. Braam J. In touch: plant responses to mechanical stimuli. New Phytol. 2005:165:373-89.

34. De Luca PA, Vallejo-Marín M. What's the 'buzz' about? The ecology and evolutionary significance of buzz-pollination. Curr Opin Plant Biol. 2013;16:429-35

35. Hegland SJ, Nielsen A, Lázaro A, Bjerknes A-L, Totland Ø. How does climate warming affect plant-pollinator interactions? Ecol Lett. 2009;12:184-95.

36. Kerr JT, Pindar A, Galpern P, Packer L, Potts SG, Roberts SM, et al. Climate change impacts on bumblebees converge across continents. Science. 2015;349:177-80.

37. Polce C, Garratt MP, Termansen M, Ramirez-Villegas J, Challinor AJ, Lappage MG, et al. Climate-driven spatial mismatches between British orchards and their pollinators: increased risks of pollination deficits. Glob Chang Biol. 2014;20:2815-28.

38. Schweiger O, Biesmeijer JC, Bommarco R, Hickler T, Hulme PE, Klotz S, et al. Multiple stressors on biotic interactions: how climate change and alien species interact to affect pollination. Biol Rev. 2010;85(4):777-95.

39. Soroye P, Newbold T, Kerr J. Climate change contributes to widespread declines among bumble bees across continents. Science. 2020;367:685-8

40. Martín J, López P. Effects of global warming on sensory ecology of rock lizards: increased temperatures alter the efficacy of sexual chemical signals. Funct Ecol. 2013;27:1332-40.

41. Sentis A, Ramon-Portugal F, Brodeur J, Hemptinne J-L. The smell of change: warming affects species interactions mediated by chemical information. Glob Chang Biol. 2015;21:3586-94.

42. Takkis $K$, Tscheulin T, Petanidou T. Differential effects of climate warming on the nectar secretion of early- and late-flowering mediterranean plants. Front Plant Sci. 2018;9:874

43. Takkis K, Tscheulin T, Tsalkatis P, Petanidou T. Climate change reduces nectar secretion in two common Mediterranean plants. AoB Plants. 2015;7:plv111.

44. Rust RW. Pollination of Impatiens capensis: pollinators and nectar robbers. J Kansas Entomol Soc. 1979;52:297-308.

45. Kato M. Bumblebee visits to Impatiens spp.: pattern and efficiency. Oecologia. 1988;76:364-70.

46. Chittka L, Spaethe J. Visual search and the importance of time in complex decision making by bees. Arthropod-Plant Interact. 2007;1:37-44.
47. Oatevik K, Manson J, Thompson J. Pollination potential of male bumble bees (Bombus impatiens): movement patterns and pollen-transfer efficiency. J Pollinat Ecol. 2010;2:21-6.

48. Spaethe J, Tautz J, Chittka L. Visual constraints in foraging bumblebees: flower size and color affect search time and flight behavior. Proc Natl Acad Sci. 2001;98:3898-903.

49. Spaethe J, Brockmann A, Halbig C, Tautz J. Size determines antennal sensitivity and behavioral threshold to odors in bumblebee workers. Naturwissenschaften. 2007;94:733-9.

50. Hejda M. What is the impact of Impatiens parviflora on diversity and composition of herbal layer communities of temperate forests? PLOS ONE. 2012;7:e39571.

51. Hejda M, Pyšek P. What is the impact of Impatiens glandulifera on species diversity of invaded riparian vegetation? Biol Conserv. 2006;132:143-52.

52. Sutherland JP, Sullivan MS, Poppy GM. Distribution and abundance of aphidophagous hoverflies (Diptera: Syrphidae) in wildflower patches and field margin habitats: Aphidophagous hoverflies in wildflower patches. Agric For Entomol. 2001;3:57-64.

53. Wratten SD, Bowie MH, Hickman JM, Evans AM, Sedcole JR, Tylianakis JM. Field boundaries as barriers to movement of hover flies (Diptera: Syrphidae) in cultivated land. Oecologia. 2003;134:605-11.

54. Tuell JK, Isaacs R. Weather during bloom affects pollination and yield of highbush blueberry. J Econ Entomol. 2010;103:557-62.

55. Osborne JL, Martin AP, Carreck NL, Swain JL, Knight ME, Goulson D, et al. Bumblebee flight distances in relation to the forage landscape. J Anim Ecol. 2008;77:406-15.

56. Visscher PK, Seeley TD. Foraging strategy of honeybee colonies in a temperate deciduous forest. Ecology. 1982;63:1790.

57. Burkle LA, Marlin JC, Knight TM. Plant-pollinator interactions over 120 years: loss of species, co-occurrence, and function. Science. 2013;339:1611-5.

58. Miller-Struttmann NE, Galen C. High-altitude multi-taskers: bumble bee food plant use broadens along an altitudinal productivity gradient. Oecologia. 2014;176:1033-45.

59. Miller-Struttmann NE, Geib JC, Franklin JD, Kevan PG, Holdo RM, EbertMay $\mathrm{D}$, et al. Functional mismatch in a bumble bee pollination mutualism under climate change. Science. 2015;349:1541-4.

60. Olesen JM, Bascompte J, Elberling H, Jordano P. Temporal dynamics in a pollination network. Ecology. 2008;89:1573-82.

61. Kudo G, Nishikawa Y, Kasagi T, Kosuge S. Does seed production of spring ephemerals decrease when spring comes early? Seed-set of spring ephemerals. Ecol Res. 2004;19:255-9.

62. Memmott J, Craze PG, Waser NM, Price MV. Global warming and the disruption of plant-pollinator interactions. Ecol Lett. 2007;10:710-7.

63. Thomson DM. Local bumble bee decline linked to recovery of honey bees, drought effects on floral resources. Ecol Lett. 2016;19:1247-55.

64. Chung H, Carroll SB. Wax, sex and the origin of species: dual roles of insect cuticular hydrocarbons in adaptation and mating. Bioessays. 2015;37:822-30.

65. Holze H, Schrader L, Buellesbach J. Advances in deciphering the genetic basis of insect cuticular hydrocarbon biosynthesis and variation. Heredity. 2020. https://doi.org/10.1038/s41437-020-00380-y.

66. Goldberg L. Patterns of nectar production and composition, and morphology of floral nectaries in Helicteres guazumifolia and Helicteres baruensis (Sterculiaceae): two sympatric species from the Costa Rican tropical dry forest. Rev Biol Trop. 2009;57:17.

67. Belsky JE, Camp AA, Lehmann DM. The importance of males to bumble bee (Bombus Species) nest development and colony viability. 2020;:16.

68. Cameron S. Brood care by males of polistes major (Hymenoptera: Vespidae). J Kansas Entomol Soc. 1986;59:183-5.

69. Baer B, Schmid-Hempel P. Sperm influences female hibernation success, survival and fitness in the bumble-bee Bombus terrestris. Proc R Soc B. 2005;272:319-23.

70. Greeff M, Schmid-Hempel P. Sperm reduces female longevity and increases melanization of the spermatheca in the bumblebee Bombus terrestris L. Insect Soc. 2008;55:313-9.

71. Najberek K, Solarz W, Gąsienica-Staszeczek M, Olejniczak P. Role of enemy release and hybridization in the invasiveness of Impatiens balfourii and I. glandulifera. J Plant Res in review. 
72. Najberek K, Okarma H, Chmura D, Król W, Walusiak E, Solarz W. Enemy pressure exerted on alien and native plants may differ between montane and lowland regions. Arthropod-Plant Interact. 2020;14:275-87.

73. Galen C. Why do flowers vary? BioScience. 1999;49:631-40.

74. Galen C. The effects of nectar thieving ants on seedset in floral scent morphs of Polemonium viscosum. Oikos. 1983;41:245.

75. IMWM. Air temperature. Extreme temperatures in August - thermal hazards risk. In: Climate of Poland 2020. Institute of Meteorology and Water Management - National Research Institute; 2021. p. 19. https://www. imgw.pl/sites/default/files/2021-04/imgw-pib-klimat-polski-2020-oprac owanie-final-eng-rozkladowki-min.pdf.

76. Burnham K, Anderson D. Model selection and multimodel inference: a practical information-theoretic approach. 2nd ed. New York: SpringerVerlag; 2002
77. Corp IBM. IBM SPSS statistics for windows, version 24. Armonk: IBM Corp; 2016.

78. R Development Core Team. R: A language and environment for statistical computing. Vienna: The R Foundation for Statistical Computing; 2015.

79. Bolker B, Skaug H, Magnusson A, Nielsen A. Getting started with the glmmADMB package. 2012. http://glmmadmb.r-forge.r-project.org/. Accessed 21 Mar 2017.

80. Miller R, Owens SJ, Rørslett B. Plants and colour: flowers and pollination. Opt Laser Technol. 2011:43:282-94.

\section{Publisher's Note}

Springer Nature remains neutral with regard to jurisdictional claims in published maps and institutional affiliations.
Ready to submit your research? Choose BMC and benefit from:

- fast, convenient online submission

- thorough peer review by experienced researchers in your field

- rapid publication on acceptance

- support for research data, including large and complex data types

- gold Open Access which fosters wider collaboration and increased citations

- maximum visibility for your research: over 100M website views per year

At BMC, research is always in progress.

Learn more biomedcentral.com/submissions 